\title{
Metabolic syndrome is associated with change in subclinical arterial stiffness - A community-based Taichung Community Health Study
}

\author{
Chia-Ing Li ${ }^{1,2,3}$, Sharon LR Kardia ${ }^{4}$, Chiu-Shong Liu' ${ }^{2,5}$, Wen-Yuan Lin ${ }^{2,5}$, Chih-Hsueh Lin², ${ }^{2,5}$ Yi-Dar Lee ${ }^{6,7}$, \\ Fung-Chang Sung ${ }^{3}$, Tsai-Chung Li $i^{8,9^{*}}$ and Cheng-Chieh Lin ${ }^{2,5,9^{*}}$
}

\begin{abstract}
Background: The aim of this study was to evaluate the effect of MetS on arterial stiffness in a longitudinal study.

Methods: Brachial-ankle pulse wave velocity (baPWV), a measurement interpreted as arterial stiffness, was measured in 1518 community-dwelling persons at baseline and re-examined within a mean follow-up period of 3 years. Multivariate linear regression with generalized estimating equations (GEE) were used to examine the longitudinal relationship between MetS and its individual components and baPWV, while multivariate logistic regression with GEE was used to examine the longitudinal relationship between MetS and its individual components and the high risk group with arterial stiffness.

Results: Subjects with MetS showed significantly greater baPWV at the end point than those without MetS, after adjusting for age, gender, education, hypertension medication and mean arterial pressure (MAP). MetS was associated with the top quartile of baPWV (the high-risk group of arterial stiffness, adjusted odds ratio [95\% confidence interval] 1.52 [1.21-1.90]), and a significant linear trend of risk for the number of components of MetS was found ( $p$ for trend $<$ 0.05). In further considering the individual MetS component, elevated blood pressure and fasting glucose significantly predicted a high risk of arterial stiffness (adjusted OR [95\% Cl] 3.72 [2.81-4.93] and 1.35 [1.08-1.68], respectively).
\end{abstract}

Conclusions: MetS affects the subject's progression to arterial stiffness. Arterial stiffness increased as the number of MetS components increased. Management of MetS is important for preventing the progression to advanced arterial stiffness.

Keywords: metabolic syndrome, pulse wave velocity, arterial stiffness

\section{Background}

Metabolic syndrome (MetS), defined as a cluster of features such as visceral obesity, impaired glucose tolerance, dyslipidemia, hypergtriglyceridemia, and elevated blood pressure $[1,2]$, is highly prevalent all over the world [3-12]. MetS has been known as a critical risk factor in the incidence of type 2 diabetes and in cardiovascular outcome $[1,13,14]$. People with MetS have higher allcause or cardiovascular mortality than those without MetS [15-17]. Arterial stiffness, a pathological condition with vascular damage, is a cardiovascular outcome of

\footnotetext{
* Correspondence: tcli@mail.cmu.edu.tw; cclin@mail.cmuh.org.tw

${ }^{2} \mathrm{~S}$ chool of Medicine, College of Medicine, China Medical University, Taichung, Taiwan

${ }^{8}$ Institute of Biostatistics, China Medical University, Taichung, Taiwan Full list of author information is available at the end of the article
}

MetS. In clinical practice, pulse wave velocity (PWV) is widely used to reflect arterial stiffness. A noninvasive brachial-ankle pulse wave velocity (baPWV) measurement, which is performed more easily than carotidfemoral PWV measurement, has been used as a marker for screening vascular damage and cardiovascular risk in the general population $[18,19]$, in diabetes patients $[20,21]$, in hypertension patients [22,23], in patients with end-stage renal disease $[24,25]$, and in women with systemic lupus erythematosus [26].

The association of MetS with arterial stiffness has been investigated in many studies [27-31]; however, most of these studies were cross-sectional [27-29,31] Studies explored the longitudinal effect of MetS on arterial stiffeness in specific subjects, such as patients who were systemic lupus erythematosus [32], patients who were 
newly detected suspected hypothyroidism [33], and persons who received work-related health check-up [34] or general health check-up [35]. None of them was community-based study. One study reported a longitudinal relation between PWV and MetS only in men workers [34]. Another 6-year follow-up study perfomed by Safar et al explored this relationship in subjects selected from receiving general health check-up population with prevalence of elevated blood pressure of 50\% [35]. Moreover, high prevalence of diabetes and dyslipidemia in the study by Safar et al was found. It is very likely to have Berkson's bias in their study [36]. Previous study showed the association may be found significantly in clinical-based studies, but not in community-based studies [37]. Our study is the first community-based study using the probability sampling method to select a random sample from a welldefined population. Identifying the effect of MetS on arterial stiffness using a longitudinal study in a community-based population can provide information for the management of MetS and thereby prevent progression to advanced arterial vascular disease. Therefore, the objective of the current study was to evaluate the longitudinal effect of MetS on baPWV by considering mean arterial pressure (MAP) and the use of hypertension medicine to reduce the influence of blood pressure on baPWV.

\section{Methods}

\section{Study sample}

This was a population-based follow-up study. The design and selection criteria of the Taichung Community Health Study (TCHS) have been described previously [4]. Briefly, 4, 280 individuals were randomly selected from Taichung City, Taiwan to be representative of its residents in terms of sex and age (aged 40 and over). Data on 2, 359 individuals (about $66.83 \%$ of the original sample) were collected from 2004-2005, and 2, 311 survivors were contacted 3 years later for re-examination. A total of 1, 648 subjects were followed (overall follow-up rate, $71.3 \%$ ) before the end of July, 2009. Of those, 28 were excluded from this analysis because they did not have a baPWV measurement at baseline or follow-up, 100 were excluded because they had suspected peripheral arterial stiffness (ankle-brachial index $<0.9$ at baseline), and 2 were excluded because of missing smoking status at baseline. In the end, 1, 518 individuals (mean age, 56 years; 49\% women) remained eligible for data analysis. All subjects signed an informed consent form before data collection.

\section{Measurements}

\section{Anthropometric measurements and laboratory} examination

All study subjects underwent a physical examination measuring height, waist circumference (WC), and blood pressure by trained staff at baseline, as well as at the endpoint. MAP was calculated as $(2 \times$ diastolic blood pressure + systolic blood pressure $) \div 3$. Blood was drawn with minimal trauma from an antecubital vein in the morning, after a 12-hour overnight fasting, and was sent for analysis within four hours of collection. Biochemical markers such as HDL cholesterol, triglyceride, and fasting glucose were analyzed by a biochemical autoanalyzer (Beckman Coluter, Lx-20, USA) at the Clinical Laboratory Department of China Medical University Hospital.

\section{Sociodemographic factors, lifestyle factors and medical history}

Data on sociodemographic factors (including age, gender and education), lifestyle factors, and medical history were collected by self-administered questionnaires. Lifestyle factors, such as smoking and alcohol drinking history, were categorized as never and former/current. We collected self-reported personal medical histories, including diabetes and hypertension medication at the baseline and follow-up examination.

\section{MetS and its components}

MetS was defined clinically, based on the presence of three or more of the following American Heart Association and the National Heart Lung Blood Institute(AHA/ NHLBI) MetS criteria [2]: (1) central obesity (WC $\geq 90$ $\mathrm{cm}$ in men, and ${ }^{3} 80 \mathrm{~cm}$ in women), (2) high triglycerides level $\left({ }^{3} 1.7 \mathrm{mmol} / \mathrm{L}\right.$ or on drug treatment for elevated triglycerides), (3) low HDL-C level $(<1.03 \mathrm{mmol} / \mathrm{L}$ in men and $<1.30 \mathrm{mmol} / \mathrm{L}$ in women or on drug treatment for reduced HDL-C), (4) high blood pressure (systolic BP ${ }^{3} 130 \mathrm{mmHg}$ or diastolic $\mathrm{BP}{ }^{3} 85 \mathrm{mmHg}$ or under antihypertensive drug treatment in a patient with a history of hypertension), and (5) high fasting plasma glucose concentration $\left({ }^{3} 5.5 \mathrm{mmol} / \mathrm{L}\right.$ or on drug treatment for elevated glucose). Diabetes was defined as fasting plasma glucose concentration ${ }^{3} 7.0 \mathrm{mmol} / \mathrm{L}$ or on drug treatment for diabetes. Hypertension was defined as systolic BP ${ }^{3} 140 \mathrm{mmHg}$ or diastolic $\mathrm{BP}{ }^{3} 90 \mathrm{mmHg}$ or on drug treatment for hypertension.

\section{Longitudinal changes in arterial stiffness}

BaPWV, presenting for arterial stiffness, was measured non-invasively with subjects in the supine position and with a VP-1000 automated PWV/ABI analyzer (PWV/ ABI; Colin Co. Ltd., Komaki, Japan) attached to the four limbs [38]. For every subject, the maximum of the left and right baPWV was chosen at baseline and at followup. The change in baPWV was calculated as re-examined baPWV subtracting baseline baPWV.

\section{Statistical analysis}

Continuous variables were reported as mean \pm standard deviation (SD) and categorical variables were reported 
as percentage ( $95 \%$ confidence intervals, abbreviated as $\mathrm{CI})$. The variables that predicted the baPWV change were evaluated by analysis of covariate with baPWV at baseline as covariate due to its high impact on the baPWV change. Moreover, to explore the effect of MetS and its components on baPWV, three multivariate models were used. First, the longitudinal effect of MetS and the number of components on the change baPWV at follow-up were examined using multivariate linear regression with the generalized estimating equations (GEE) method. Second, we further evaluated how the longitudinal effect of individual MetS components on baPWV was affected by the other components being considered sequentially, using hierarchical linear regression analysis with the GEE approach. The order of entering the variables was elevated blood pressure, fasting glucose, WC, triglyceride, and low HDL cholesterol after adjustment. Last, the top quartile of baseline baPWV was used as the cutoff point to classify the high risk group with arterial stiffness. Multivariate logistic regression with the GEE approach was used to analyze the longitudinal effect of MetS and its components on arterial stiffness. We treated the number of MetS components as continuous variables to examine the linear trend on the risk of arterial stiffness. All reported $p$ values were those of the two-sided tests; statistical significance was set at $p<0.05$. All analyses were performed using SAS version 9.1 (SAS Institute Inc, Cary, $\mathrm{NC}$ ).

\section{Results}

Compared with individuals without MetS, a higher proportion of individuals with MetS were older, male, with $\leq$ 9 years of educational attainment, former or current smokers, former or current drinkers, and users of hypertension, hyperlipidemia, and diabetes medication (Table 1).

The baseline baPWV and changes in baPWV during the follow-up period, according to the various groups of sociodemographic factors, health factors, and medication after adjusting for baPWV at baseline, are illustrated in Table 2 . Larger increases in changes of baPWV were observed in those with an older age, lower educational level, and use of medication for hypertension, hyperlipidemia, and diabetes at baseline (all $p<0.05$ ). The changes were not significantly different in terms of marital status and health factors at baseline, such as smoking and drinking.

Subjects with MetS had a higher mean value of baPWV at baseline. Compared to subjects without MetS, subjects with MetS had a significantly greater 3year mean change of baPWV (-9.5 vs. 31.1, after adjusting for baPWV at baseline) (Table 3). The greater the number of MetS components at baseline, the larger the adjusted mean changes of baPWV ( $p$ for trend $<0.001$ ).
Table 1 Baseline characteristics of subjects with and without metabolic syndrome

\begin{tabular}{|c|c|c|c|c|c|}
\hline \multirow[b]{2}{*}{ Variable at baseline } & \multicolumn{2}{|c|}{ Non-MetS ${ }^{\dagger}$} & \multicolumn{2}{|c|}{ MetS $^{\dagger}$} & \multirow[b]{2}{*}{$p$ value } \\
\hline & $\mathrm{n}$ & $(\%)$ & $\mathrm{n}$ & (\%) & \\
\hline \multicolumn{6}{|l|}{ Sociodemographic factors } \\
\hline Age & & & & & $<0.001$ \\
\hline $40-50$ years & 372 & $(39.2)$ & 128 & $(22.5)$ & \\
\hline $51-60$ years & 335 & $(35.3)$ & 187 & $(32.9)$ & \\
\hline $61-70$ years & 151 & $(15.9)$ & 140 & $(24.7)$ & \\
\hline$>70$ years & 92 & (9.6) & 113 & $(19.9)$ & \\
\hline Gender & & & & & $<0.001$ \\
\hline Female & 521 & $(54.8)$ & 227 & $(40.0)$ & \\
\hline Male & 429 & $(45.2)$ & 341 & $(60.0)$ & \\
\hline Education & & & & & $<0.001$ \\
\hline$\leq 9$ years & 268 & $(28.3)$ & 231 & $(40.7)$ & \\
\hline $10-12$ years & 471 & $(49.7)$ & 256 & $(45.2)$ & \\
\hline$>12$ years & 208 & $(22.0)$ & 80 & $(14.1)$ & \\
\hline Married status & & & & & 0.691 \\
\hline Not currently married & 154 & $(16.3)$ & 87 & $(15.4)$ & \\
\hline Married & 790 & (83.7) & 478 & $(84.6)$ & \\
\hline \multicolumn{6}{|l|}{ Lifestyle factors } \\
\hline Smoking & & & & & $<0.001$ \\
\hline Never & 744 & $(78.3)$ & 377 & $(66.4)$ & \\
\hline Former/Current & 206 & $(21.7)$ & 191 & (33.6) & \\
\hline Drinking & & & & & 0.008 \\
\hline Never & 691 & $(72.7)$ & 376 & $(66.2)$ & \\
\hline Former/Current & 259 & $(27.3)$ & 192 & (33.8) & \\
\hline \multicolumn{6}{|l|}{ Medication } \\
\hline \multicolumn{6}{|l|}{ Hypertension } \\
\hline Yes & 139 & $(14.6)$ & 265 & $(46.7)$ & $<0.001$ \\
\hline \multicolumn{6}{|l|}{ Hyperlipidemia } \\
\hline Yes & 51 & (5.4) & 132 & $(23.2)$ & $<0.001$ \\
\hline \multicolumn{6}{|l|}{ Diabetes } \\
\hline Yes & 20 & (2.1) & 103 & (18.1) & $<0.001$ \\
\hline
\end{tabular}

† MetS, metabolic syndrome

Analysis of the longitudinal effect of MetS on baPWV using GEE models showed that subjects with MetS had a higher mean baPWV of $36.2(p<0.001)$ after adjusting for age, gender, education, smoke status, time-dependent hypertension medication, and time-dependent MAP (Figure 1). Considering the longitudinal effect of the number of MetS components on baPWV, the differences in baPWV in subjects with 1,2 and more than or equal to $3 \mathrm{MetS}$ components versus those without a MetS component were 38.2, 46.7 and 76.3, respectively (all $p<0.001$ ) (Figure 1).

In exploring the independent effects of MetS components, hierarchical regression analysis with the GEE approach demonstrated that elevated blood pressure (adjusted regression coefficients $[\beta]=28.3, p<0.05$ ) and fasting glucose $(\mathrm{b}=51.4, p<0.001)$ had an independent effect on longitudinal baPWV (Table 4). 
Table 2 Brachial-ankle pulse wave velocity (baPWV) at baseline and its changes adjusted for baPWV at baseline during the period of follow-up of baseline characteristics

\begin{tabular}{|c|c|c|c|c|c|c|}
\hline \multirow[b]{2}{*}{ Variable at baseline } & \multirow[b]{2}{*}{ n } & \multicolumn{2}{|c|}{ baPWV at baseline } & \multicolumn{3}{|c|}{ Changes of baPWV during follow-up period* } \\
\hline & & Mean & $\pm S D$ & Adj & $\pm \mathrm{SE}$ & $\mathrm{p}$ value \\
\hline \multicolumn{7}{|l|}{ Sociodemographic factors } \\
\hline Age & & & & & & $<0.001$ \\
\hline $40-50$ years & 500 & 1365.1 & \pm 212.7 & -62.6 & \pm 10.8 & \\
\hline $51-60$ years & 522 & 1552.2 & \pm 281.5 & -18.4 & \pm 9.6 & \\
\hline $61-70$ years & 291 & 1789.3 & \pm 366.2 & 70.9 & \pm 13.2 & \\
\hline$>70$ years & 205 & 2147.2 & \pm 459.2 & 141.0 & \pm 18.1 & \\
\hline Gender & & & & & & 0.101 \\
\hline Female & 770 & 1674.4 & \pm 397.6 & -3.8 & \pm 8.3 & \\
\hline Male & 748 & 1556.6 & \pm 399.3 & 14.9 & \pm 8.2 & \\
\hline Education & & & & & & 0.004 \\
\hline$\leq 9$ years & 499 & 1736.7 & \pm 443.3 & 34.3 & \pm 10.2 & \\
\hline $10-12$ years & 727 & 1566.5 & \pm 372.9 & -6.7 & \pm 8.4 & \\
\hline$>12$ years & 288 & 1532.1 & \pm 353.0 & -10.3 & \pm 13.3 & \\
\hline Married status & & & & & & 0.398 \\
\hline Not currently married & 241 & 1660.5 & \pm 446.4 & 17.0 & \pm 14.6 & \\
\hline Married & 1268 & 1607.3 & \pm 393.3 & 3.6 & \pm 6.3 & \\
\hline \multicolumn{7}{|l|}{ lifestyle factors } \\
\hline Smoking & & & & & & 0.346 \\
\hline Never & 1121 & 1603.1 & \pm 415.1 & 2.4 & \pm 6.7 & \\
\hline Former/Current & 397 & 1653.9 & \pm 363.2 & 14.9 & \pm 11.3 & \\
\hline Drinking & & & & & & 0.553 \\
\hline Never & 1067 & 1623.6 & \pm 416.8 & 7.9 & \pm 6.9 & \\
\hline Former/Current & 451 & 1599.4 & \pm 367.0 & 0.4 & \pm 10.6 & \\
\hline \multicolumn{7}{|l|}{ Medication } \\
\hline Hypertension & & & & & & $<0.001$ \\
\hline No & 1197 & 1541.9 & \pm 355.3 & -8.6 & \pm 6.6 & \\
\hline Yes & 304 & 1903.1 & \pm 440.7 & 68.8 & \pm 13.6 & \\
\hline Hyperlipidemia & & & & & & 0.002 \\
\hline No & 1401 & 1604.9 & \pm 397.8 & 1.3 & \pm 6.0 & \\
\hline Yes & 93 & 1779.7 & \pm 397.3 & 77.7 & \pm 23.3 & \\
\hline Diabetes & & & & & & $<0.001$ \\
\hline No & 1415 & 1591.3 & \pm 382.0 & -3.8 & \pm 5.9 & \\
\hline Yes & 94 & 1997.6 & \pm 476.7 & 146.7 & \pm 23.7 & \\
\hline
\end{tabular}

SD, standard deviation; SE, standard error

* The difference in each variables was calculated by analysis of covariance with baPWV at baseline as covariate.

Table 3 Brachial-ankle pulse wave velocity (baPWV) at baseline and its changes with baPWV at baseline as covariate according to MetS status and the number of MetS components

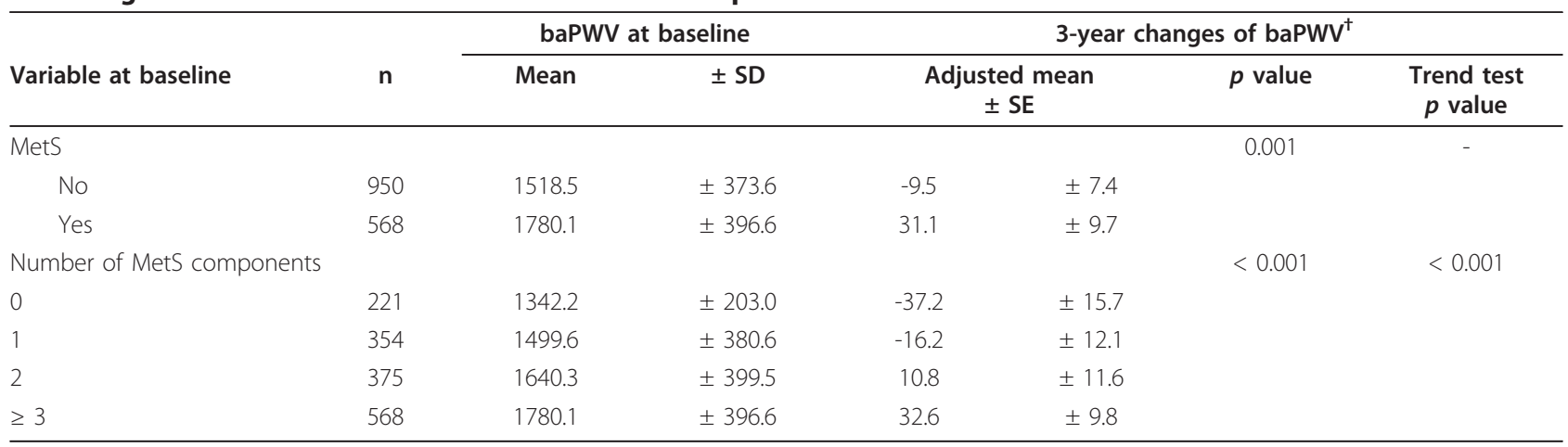

MetS, metabolic syndrome; SD, standard deviation; SE, standard error.

${ }^{\dagger}$ All values were calculated by analysis of covariance with baPWV at baseline as covariate. 


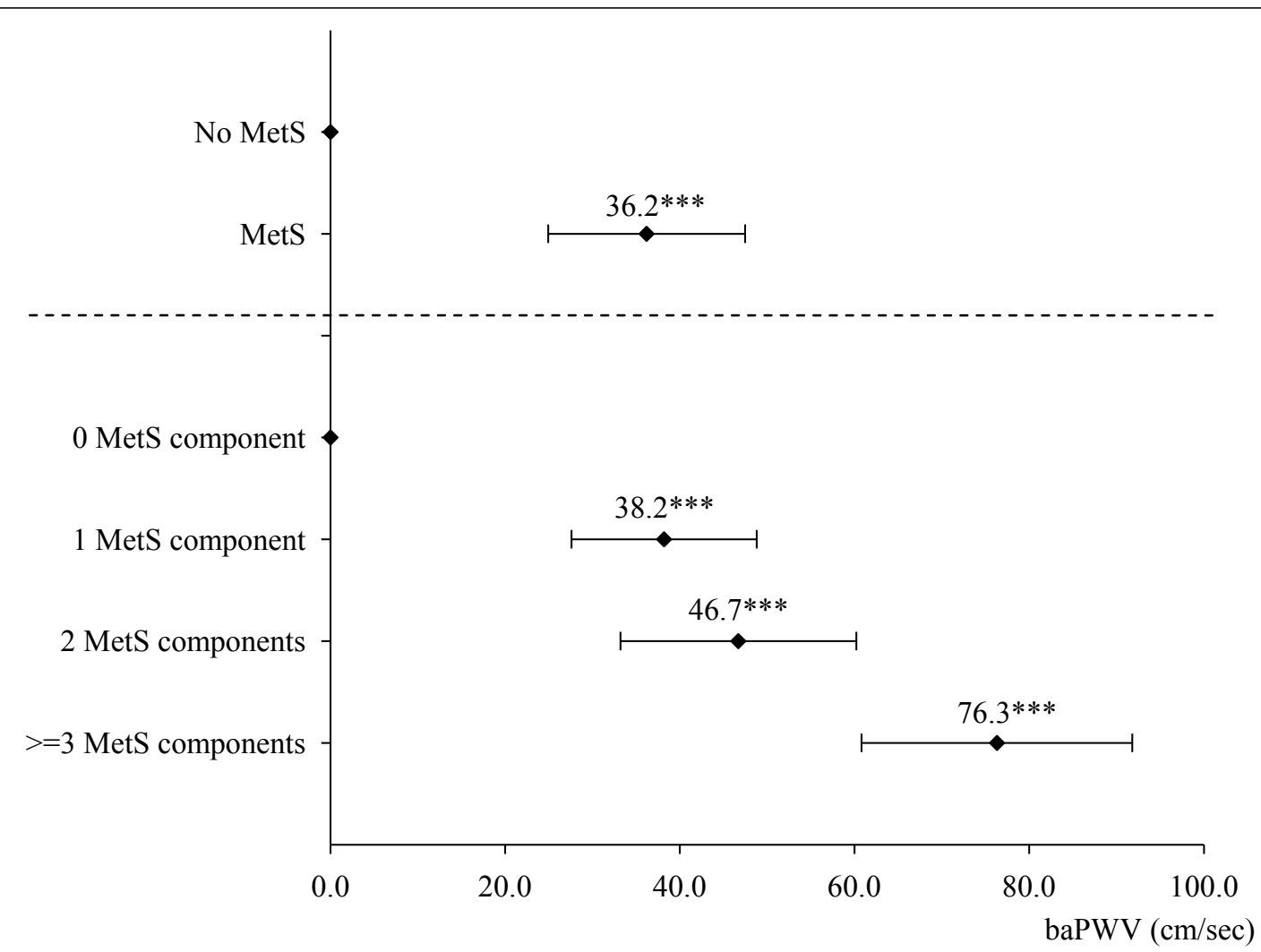

Figure 1 Multivariate linear regression with the use of generalized estimating equations of longitudinal brachial-ankle pulse wave velocity (baPWV) based on metabolic syndrome (MetS) and its number of components. Both models were adjusted for age, gender, education, smoking status at baseline, time-dependent hypertension medication, and time-dependent mean arterial pressure. Point estimates and standard errors of baPWV for MetS and each number of MetS components were shown as rhombic point and horizontal bar. ${ }^{* * *} \mathrm{p}<0.001$

The cutoff point of the top quartile of baseline baPWV was $1813 \mathrm{~cm} / \mathrm{s}$. The adjusted odds of the highrisk group with arterial stiffness for MetS were 1.52 (95\% confidence interval [CI], 1.21-1.90). The adjusted odds ratios (ORs) of the high-risk group with arterial stiffness were 3.31 (95\% CI, 2.06-5.33), 4.21 (95\% CI, 2.57-6.91), and 5.24 (95\% CI, 3.20-8.57) in subjects with 1,2 , and $\geq 3$ MetS components after multivariate

Table 4 Hierarchical multivariate linear regression with generalized estimating equation analysis for brachial-ankle pulse wave velocity (baPWV) changes in 1518 subjects during a 3-year follow up

\begin{tabular}{|c|c|c|c|c|c|}
\hline \multirow[b]{2}{*}{ MetSt components } & \multicolumn{5}{|c|}{ Estimate $(95 \% \mathrm{Cl})$} \\
\hline & Model 1 & Model 2 & Model 3 & Model 4 & Model 5 \\
\hline Elevated blood pressure & $\begin{array}{c}\mathbf{3 2 . 3}^{*} \\
(6.2 \sim 58.3)\end{array}$ & 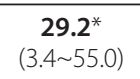 & $\begin{array}{c}29.8^{*} \\
(4.1 \sim 55.6)\end{array}$ & $\begin{array}{c}\mathbf{2 8 . 2}^{*} \\
(2.5 \sim 53.9)\end{array}$ & $\begin{array}{c}\mathbf{2 8 . 3}^{*} \\
(2.5 \sim 54.0)\end{array}$ \\
\hline Elevated fasting glucose & & $\begin{array}{c}\mathbf{5 1 . 6}^{* * *} \\
(31.7 \sim 71.4)\end{array}$ & $\begin{array}{c}\mathbf{5 2 . 5}^{\mathbf{* * *}} \\
(32.5 \sim 72.6)\end{array}$ & $\begin{array}{c}\mathbf{5 1 . 5}^{* * *} \\
(31.5 \sim 71.5)\end{array}$ & $\begin{array}{c}\mathbf{5 1 . 4}^{* * *} \\
(31.3 \sim 71.4)\end{array}$ \\
\hline Central obesity & & & $-9.5(-30.9 \sim 11.9)$ & $\begin{array}{c}-11.1 \\
(-32.6 \sim 10.4)\end{array}$ & $\begin{array}{c}-11.3 \\
(-32.8 \sim 10.2)\end{array}$ \\
\hline Elevated triglyceride & & & & $\begin{array}{c}20.8 \\
(-1.8 \sim 43.4)\end{array}$ & $\begin{array}{c}20.2 \\
(-2.6 \sim 43.0)\end{array}$ \\
\hline Low $\mathrm{HDL}^{+}$cholesterol & & & & & $\begin{array}{c}2.7 \\
(-16.9 \sim 22.3)\end{array}$ \\
\hline
\end{tabular}

$\mathrm{Cl}$, confidence interval.

${ }^{\dagger}$ MetS, metabolic syndrome; HDL, high-density lipoprotein

All models were adjusted for age, gender, education, smoking status at baseline, time-dependent hypertension medication, and time-dependent mean arterial pressure.

${ }^{*} \mathrm{p}<0.05,{ }^{* *} \mathrm{p}<0.01,{ }^{* * *} \mathrm{p}<0.001$ 
adjustment. A significant linear relationship between the adjusted OR and the number of components of MetS was found ( $p$ for trend $<0.05$ ). The adjusted ORs of the high-risk group with arterial stiffness were 3.72 (95\% CI, 2.81-4.93) and 1.35 (95\% CI, 1.08-1.68) in individuals with elevated blood pressure and fasting glucose (both $p$ $<0.05$ ) (Figure 2).

\section{Discussion}

In this 3-year community-based prospective study, we found that MetS and the MetS components independently predicted the future progression or incidence of arterial stiffness. Regarding the influence of individual components of MetS on arterial stiffness, we found that blood pressure and fasting glucose were independent determinants of longitudinal arterial stiffness progression in this general population. Moreover, they were independent risk factors for predicting the 3-year incidence of the higher risk of developing arterial stiffness.

The existence of a strong association between the presence of MetS and arterial stiffness has been shown in many cross-sectional studies [27-29]. However, the longitudinal effect of MetS on arterial stiffness in the general population has not been clarified [34,35,39]. In this longitudinal population-based study, we provided community-based evidence that MetS is an independent risk factor for progression of arterial stiffness in a random sample of Taiwaneses adults aged 40 years and over. Our findings were consistent with those of several previous studies that showed a causal relationship between MetS and arterial stiffness. In a 3-year prospective study of 2, 080 male employees in a company, Tomiyama et al. showed that subjects with persistent MetS had a higher annual rate of increase in baPWV than those with regression of MetS during the follow-up period [34]. Similar deleterious effects of MetS on aortic stiffness were found in a 6-year follow-up study of a health check-up for 476 French adults who were working and retired persons and their families [35].

In the present study, only elevated blood pressure and fasting glucose were independent predictors of progressive arterial stiffness. Tomiyama et al. [34], in their study

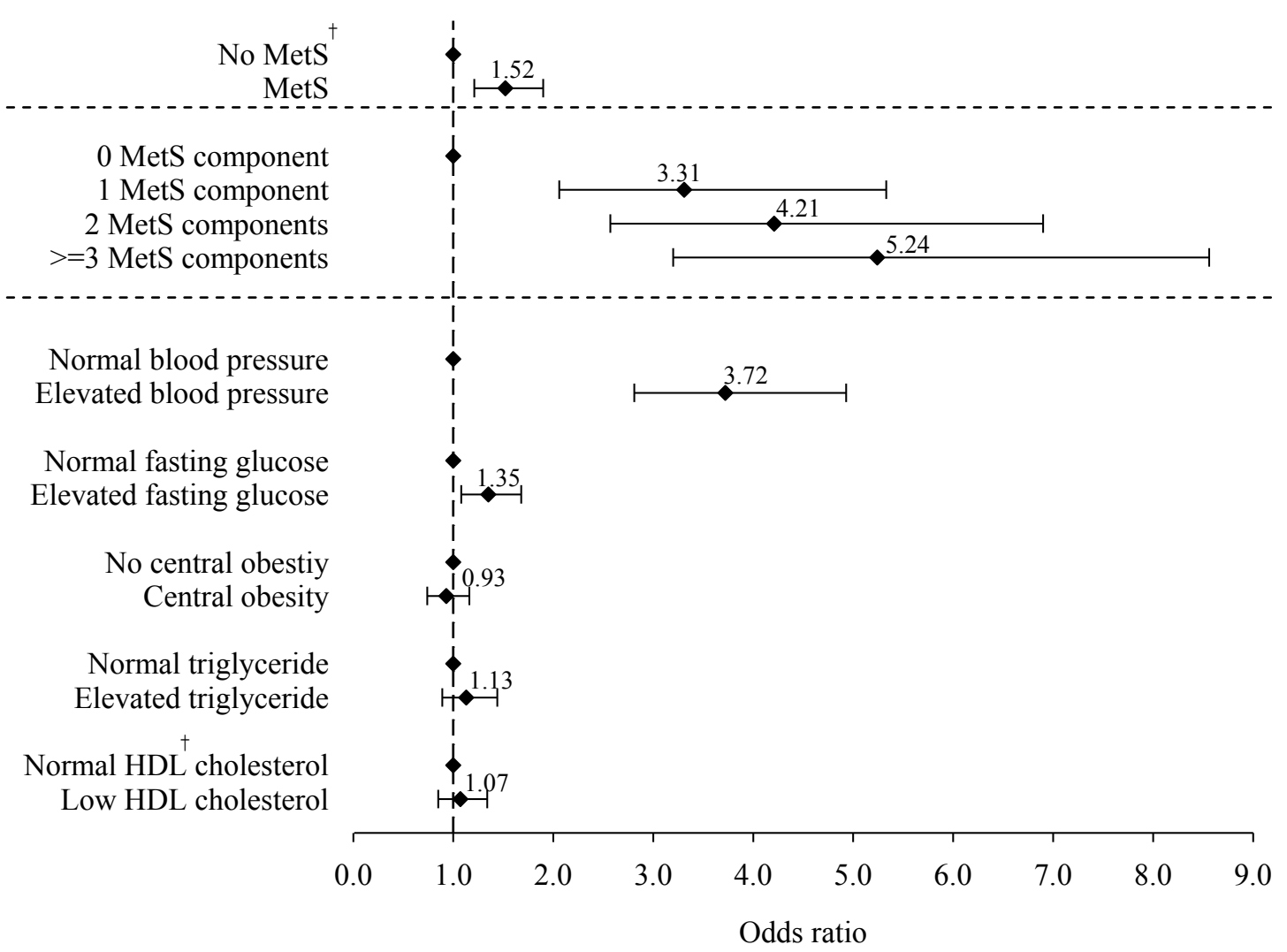

Figure 2 Multivariate-adjusted odds ratio of top quartile of brachial-ankle pulse wave velocity (baPWV) at baseline based on MetS, number of MetS components, and individual MetS components after adjusting for age, gender, education, smoking status at baseline, time-dependent hypertension medication, and time-dependent mean arterial pressure. The cut-off point of the top quartile of baseline baPWV was $1813 \mathrm{~cm} / \mathrm{s} .{ }^{\dagger}$ MetS, metabolic syndrome; HDL, high-density lipoprotein. ${ }^{*}$ The linear trend of baPWV changes in the number of MetS components in the top quartile was statistically significant. 
of 2080 male employees aged 29 to 76 years with an average of 3 years of follow-up, found elevated blood pressure and fasting glucose at baseline were independent predictors for changes in baPWV, which was consistent with our findings. Li et al [39] followed 835 young adults aged 4 to 17 years with 26.5 years in average, and found that the independent predictors of baPWV in young adults were systolic blood pressure, HDL cholesterol, and triglycerides in adulthood. However, we did not find that elevated triglyceride and low HDL cholesterol were associated with longitudinal baPWV. There are two possible reasons why Li et al.'s findings [39] were not consistent with ours. One is that they did not measure baPWV at baseline and could not correct or adjust it, which may have resulted in overestimating the effects of triglyceride and HDL cholesterol. The other is that our study lacked power to detect the effect of triglyceride and HDL cholesterol, due to the shorter follow-up period than that in Li et al's study [39].

The possible mechanism that can explain the effect of elevated blood pressure on progressive arterial stiffness is its direct effect on arterial walls. Elevated blood pressure may accelerate arterial stiffening because it forces endothelial cells and arterial smooth muscle cells to be exposed to the increase arterial wall dispensability chronically, which reflects arterial stiffening [40]. Elevated blood glucose leads to the formation and deposition of advanced glycation end-products, which promote the crosslinking of collagen that stiffens the structural components of the arterial wall [41].

This study has several strengths. First, this was a prospective study; therefore, the temporal relationship between metabolic risk factors and arterial stiffness could be clearly ascertained. Second, this was a communitybased cohort which could be representative of the general population. And lastly, our study evaluated arterial stiffness using non-invasive and simple baPWV measurement, and statistical corrections were made to prevent the influence of blood pressure. However, there are two limitations to our study. One is that our findings could not be generalized to young adults because we recruited participants aged 40 and over. The other is that the findings of our study may not be generalized to adults living in areas of less urbanization, because our sample was randomly selected from a population in a metropolitan area.

\section{Conclusions}

We found that MetS and its components of fasting glucose and blood pressure are independent predictors of the longitudinal increase in arterial stiffness. Since these predictors are associated with significant cardiovascular morbidity and mortality, our findings suggest that management of MetS to prevent progression to advanced arterial vascular disease is important.

\section{Acknowledgements}

This study was supported by grants from the National Science Council of Taiwan ROC [grant numbers NSC94-2314-B-039-024; NSC96-2628-B-039-011MY3], and the Taiwan Department of Health Clinical Trial and Research Center of Excellence [grant numbers DOH99-TD-B-111-004].

\section{Author details}

'Department of Medical Research, China Medical University Hospital, Taichung, Taiwan. ${ }^{2}$ School of Medicine, College of Medicine, China Medical University, Taichung, Taiwan. ${ }^{3}$ Department of Public health, College of Public Health, China Medical University, Taichung, Taiwan. ${ }^{4}$ Department of Epidemiology, University of Michigan, Ann Arbor, Michigan, USA. ${ }^{5}$ Department of Family Medicine, China Medical University Hospital, Taichung, Taiwan. ${ }^{6}$ Department of Psychiatric, Medical College, National Cheng-Kung University, Tainan, Taiwan. ${ }^{7}$ Bristol-Myers Squibb Ltd, Global Development \& Medical Affair, Taipei, Taiwan. ${ }^{8}$ Institute of Biostatistics, China Medical University, Taichung, Taiwan. ${ }^{9}$ Department of Healthcare Administration, College of Health Science, Asia University, Taichung, Taiwan.

\section{Authors' contributions}

CCL and TCL conceived and designed the experiments. CIL, TCL and CSL analyzed the data. WYL, CHL, YDL, and CCL participated in coordination and evaluation of data. SLK and FCS contributed to the study with their knowledge on field study. CCL, TCL and CCL wrote the paper. All authors read and approved the final manuscript.

\section{Competing interests}

The authors declare that they have no competing interests.

Received: 13 June 2011 Accepted: 17 October 2011

Published: 17 October 2011

\section{References}

1. McNeill AM, Rosamond WD, Girman CJ, Golden SH, Schmidt MI, East HE, Ballantyne CM, Heiss G: The metabolic syndrome and 11-year risk of incident cardiovascular disease in the atherosclerosis risk in communities study. Diabetes Care 2005, 28(2):385-390.

2. Executive Summary of The Third Report of The National Cholesterol Education Program (NCEP) Expert Panel on Detection, Evaluation, And Treatment of High Blood Cholesterol In Adults (Adult Treatment Panel III). JAMA 2001, 285(19):2486-2497.

3. Ford ES, Giles WH, Dietz WH: Prevalence of the metabolic syndrome among US adults: findings from the third National Health and Nutrition Examination Survey. JAMA 2002, 287(3):356-359.

4. Lin CC, Liu CS, Lai MM, Li Cl, Chen CC, Chang PC, Lin WY, Lee YD, Lin T, Li TC: Metabolic syndrome in a Taiwanese metropolitan adult population. BMC Public Health 2007, 7:239.

5. Meigs JB, Wilson PW, Nathan DM, D'Agostino RB, Williams K, Haffner SM: Prevalence and characteristics of the metabolic syndrome in the San Antonio Heart and Framingham Offspring Studies. Diabetes 2003, 52(8):2160-2167

6. Kim ES, Han SM, Kim YI, Song KH, Kim MS, Kim WB, Park JY, Lee KU: Prevalence and clinical characteristics of metabolic syndrome in a rural population of South Korea. Diabet Med 2004, 21(10):1141-1143.

7. Liu J, Hanley AJ, Young TK, Harris SB, Zinman B: Characteristics and prevalence of the metabolic syndrome among three ethnic groups in Canada. Int J Obes (Lond) 2006, 30(4):669-676.

8. Khazale NS, Haddad F: Prevalence and characteristics of metabolic syndrome in 111 Royal Jordanian Air Force pilots. Aviat Space Environ Med 2007, 78(10):968-972.

9. Oh EG, Bang SY, Hyun SS: Prevalence and Clinical Characteristics of Metabolic Syndrome for At-Risk People in a Rural Community. Metab Syndr Relat Disord 2008.

10. Park YW, Zhu S, Palaniappan L, Heshka S, Carnethon MR, Heymsfield SB: The metabolic syndrome: prevalence and associated risk factor findings in the US population from the Third National Health and Nutrition Examination Survey, 1988-1994. Arch Intern Med 2003, 163(4):427-436.

11. Florez H, Silva E, Fernandez V, Ryder E, Sulbaran T, Campos G, Calmon G, Clavel E, Castillo-Florez S, Goldberg R: Prevalence and risk factors associated with the metabolic syndrome and dyslipidemia in White, 
Black, Amerindian and Mixed Hispanics in Zulia State, Venezuela. Diabetes Res Clin Pract 2005, 69(1):63-77.

12. Ram KT, Bobby P, Hailpern SM, Lo JC, Schocken M, Skurnick J, Santoro N: Duration of lactation is associated with lower prevalence of the metabolic syndrome in midlife-SWAN, the study of women's health across the nation. Am J Obstet Gynecol 2008, 198(3):268-e261, 266.

13. Cameron AJ, Zimmet PZ, Soderberg S, Alberti KG, Sicree R, Tuomilehto J, Chitson P, Shaw JE: The metabolic syndrome as a predictor of incident diabetes mellitus in Mauritius. Diabet Med 2007, 24(12):1460-1469.

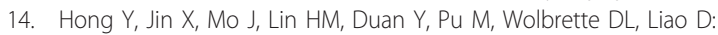
Metabolic syndrome, its preeminent clusters, incident coronary heart disease and all-cause mortality-results of prospective analysis for the Atherosclerosis Risk in Communities study. J Intern Med 2007, 262(1):113-122.

15. Ardern Cl, Janssen I: Metabolic syndrome and its association with morbidity and mortality. Appl Physiol Nutr Metab 2007, 32(1):33-45.

16. Arnlov J, Ingelsson E, Sundstrom J, Lind L: Impact of body mass index and the metabolic syndrome on the risk of cardiovascular disease and death in middle-aged men. Circulation 121(2):230-236.

17. Thomas GN, Phillips AC, Carroll D, Gale CR, Batty GD: The metabolic syndrome adds utility to the prediction of mortality over its components: The Vietnam Experience Study. Atherosclerosis 2009.

18. Yamashina A, Tomiyama H, Arai T, Hirose K, Koji Y, Hirayama Y, Yamamoto Y, Hori S: Brachial-ankle pulse wave velocity as a marker of atherosclerotic vascular damage and cardiovascular risk. Hypertens Res 2003, 26(8):615-622.

19. Kim YK: Impact of the metabolic syndrome and its components on pulse wave velocity. Korean J Intern Med 2006, 21(2):109-115.

20. Aso K, Miyata M, Kubo T, Hashiguchi H, Fukudome M, Fukushige E, Koriyama N, Nakazaki M, Minagoe S, Tei C: Brachial-ankle pulse wave velocity is useful for evaluation of complications in type 2 diabetic patients. Hypertens Res 2003, 26(10):807-813.

21. Yokoyama H, Hirasawa K, Aoki T, Ishiyama M, Koyama K: Brachial-ankle pulse wave velocity measured automatically by oscillometric method is elevated in diabetic patients with incipient nephropathy. Diabet Med 2003, 20(11):942-945

22. Dohi Y, Ohashi M, Sugiyama M, Takase H, Sato K, Ueda R: Circulating thrombomodulin levels are related to latent progression of atherosclerosis in hypertensive patients. Hypertens Res 2003, 26(6):479-483.

23. Wang JM, Su C, Wang Y, Huang YJ, Yang Z, Chen L, Wu F, Xu SY, Tao J: Elevated circulating endothelial microparticles and brachial-ankle pulse wave velocity in well-controlled hypertensive patients. J Hum Hypertens 2009, 23(5):307-315.

24. Morimoto S, Yurugi T, Aota Y, Sakuma T, Jo F, Nishikawa M, Iwasaka T, Maki K: Prognostic significance of ankle-brachial index, brachial-ankle pulse wave velocity, flow-mediated dilation, and nitroglycerin-mediated dilation in end-stage renal disease. Am J Nephrol 2009, 30(1):55-63.

25. Chen SC, Chang JM, Hwang SJ, Chen JH, Lin FH, Su HM, Chen HC: Comparison of ankle-brachial index and brachial-ankle pulse wave velocity between patients with chronic kidney disease and hemodialysis. Am J Nephrol 2009, 29(5):374-380.

26. Tso TK, Huang WN, Huang HY, Chang CK: Association of brachial-ankle pulse wave velocity with cardiovascular risk factors in systemic lupus erythematosus. Lupus 2005, 14(11):878-883.

27. Satoh H, Kishi R, Tsutsui H: Metabolic syndrome is a significant and independent risk factor for increased arterial stiffness in Japanese subjects. Hypertens Res 2009, 32(12):1067-1071.

28. Kovaite M, Petrulioniene Z, Ryliskyte L, Badariene J, Dzenkeviciute V, Cypiene A, Laucevicius A, Polena S, Gintautas J: Systemic assessment of arterial wall structure and function in metabolic syndrome. Proc West Pharmacol Soc 2007, 50:123-130.

29. Teramura M, Emoto M, Araki T, Yokoyama H, Motoyama K, Shinohara K, Mori K, Koyama H, Shoji T, Inaba M, et al: Clinical impact of metabolic syndrome by modified NCEP-ATPIII criteria on carotid atherosclerosis in Japanese adults. J Atheroscler Thromb 2007, 14(4):172-178.

30. Nam JS, Park JS, Cho MH, Jee SH, Lee HS, Ahn CW, Lowe WL, Kim KR: The association between pulse wave velocity and metabolic syndrome and adiponectin in patients with impaired fasting glucose: cardiovascular risks and adiponectin in IFG. Diabetes Res Clin Pract 2009, 84(2):145-151.

31. Ahluwalia N, Drouet L, Ruidavets JB, Perret B, Amar J, Boccalon H, HanaireBroutin $\mathrm{H}$, Ferrieres J: Metabolic syndrome is associated with markers of subclinical atherosclerosis in a French population-based sample. Atherosclerosis 2006, 186(2):345-353.

32. Sabio JM, Vargas-Hitos J, Zamora-Pasadas M, Mediavilla JD, Navarrete N, Ramirez A, Hidalgo-Tenorio C, Jaimez L, Martin J, Jimenez-Alonso J: Metabolic syndrome is associated with increased arterial stiffness and biomarkers of subclinical atherosclerosis in patients with systemic lupus erythematosus. J Rheumatol 2009, 36(10):2204-2211.

33. Nagasaki T, Inaba M, Yamada S, Kumeda Y, Hiura Y, Nishizawa Y: Changes in brachial-ankle pulse wave velocity in subclinical hypothyroidism during normalization of thyroid function. Biomed Pharmacother 2007, 61(8):482-487.

34. Tomiyama H, Hirayama Y, Hashimoto H, Yambe M, Yamada J, Koji Y, Motobe K, Shiina K, Yamamoto Y, Yamashinai A: The effects of changes in the metabolic syndrome detection status on arterial stiffening: a prospective study. Hypertens Res 2006, 29(9):673-678.

35. Safar ME, Thomas F, Blacher J, Nzietchueng R, Bureau JM, Pannier B, Benetos A: Metabolic syndrome and age-related progression of aortic stiffness. J Am Coll Cardiol 2006, 47(1):72-75.

36. Berkson J: Limitations of the application of fourfold table analysis to hospital data. Biometrics 1946, 2(3):47-53.

37. Feinstein AR, Walter SD, Horwitz Rl: An analysis of Berkson's bias in casecontrol studies. J Chronic Dis 1986, 39(7):495-504.

38. Yamashina A, Tomiyama H, Takeda K, Tsuda H, Arai T, Hirose K, Koji Y, Hori S, Yamamoto Y: Validity, reproducibility, and clinical significance of noninvasive brachial-ankle pulse wave velocity measurement. Hypertens Res 2002, 25(3):359-364.

39. Li S, Chen W, Srinivasan SR, Berenson GS: Childhood blood pressure as a predictor of arterial stiffness in young adults: the bogalusa heart study. Hypertension 2004, 43(3):541-546.

40. Kass DA: Ventricular arterial stiffening: integrating the pathophysiology. Hypertension 2005, 46(1):185-193.

41. Wautier JL, Guillausseau PJ: Diabetes, advanced glycation endproducts and vascular disease. Vasc Med 1998, 3(2):131-137.

\section{Pre-publication history}

The pre-publication history for this paper can be accessed here: http://www.biomedcentral.com/1471-2458/11/808/prepub

doi:10.1186/1471-2458-11-808

Cite this article as: Li et al:: Metabolic syndrome is associated with change in subclinical arterial stiffness - A community-based Taichung Community Health Study. BMC Public Health 2011 11:808.

\section{Submit your next manuscript to BioMed Central and take full advantage of:}

- Convenient online submission

- Thorough peer review

- No space constraints or color figure charges

- Immediate publication on acceptance

- Inclusion in PubMed, CAS, Scopus and Google Scholar

- Research which is freely available for redistribution

Submit your manuscript at www.biomedcentral.com/submit
C Biomed Central 